\title{
An Overview of Sleepiness Aspects Reflected in Balance Scale Model
}

\author{
Johannes van den Berg*
}

Department of Nursing, Umeå University, S-901 87 Umeå, Sweden

\begin{abstract}
This overview presents aspects that link sleepiness and are reflected in a model. Sleepiness is a common health problem today, affecting up to one-third of the population and related to many work accidents and injuries. Traffic accidents related to sleepiness are one area that has drawn a fair amount of attention. A better general understanding of sleepiness in society, including causes of sleepiness, predictors, indicators, and the risks of being sleepy, is needed. Although sleepiness and related aspects are multidisciplinary research fields that involve business, public interests, and governmental responsibilities, a comprehensive model of sleepiness and related aspects is lacking. The purpose of this overview was related to aspects of sleepiness into a simple model, balance scale, and to describe the aspects in the proposed model, which includes sleep dept, stimulations, level of sleepiness, sleepiness indicators, circadian rhythm, and the risk of an accident. This might increase the understanding how the aspects interact and affect each other. A simple model of sleepiness and related aspects has potential to facilitate the understanding between different interests in this multidisciplinary research field.
\end{abstract}

Keywords: Sleepiness, indicators, accidents, countermeasures, sleep dept, circadian rhythm.

\section{INTRODUCTION}

At some point, everyone has experienced being sleepy, longing for a good sleep, being aware of the negative effects of a sleep debt, and feeling how sleepiness affects different kinds of performance. Certainly, most of us have also taken actions to alleviate sleepiness to stay awake. When it comes to sleepiness, one might say it is basically a question of not getting enough good sleep. Sleep is as important as physical fitness and good nutrition [1]; however, the knowledge about these two latter is more widely available to the general public and health care systems than knowledge of sleep, wakefulness, and sleepiness. For instance, compare the number of weekly magazines focusing on food and diet or sports and fitness with those magazines focusing on sleep, wakefulness, and sleepiness.

Electric lightning, worldwide travel, and worldwide computerization have contributed to a 24-hour society, seven days a week. This is not without disadvantages: curtailment of sleep and sleep disturbance are side effects, with negative consequences on social life, families parenting, work performance, medical disorders, nature, and economy.

Sleepiness is one of the most common health problems today and up to one-third of the population are suffering from excessive sleepiness [2-5]. However, depending on the purpose of the scientific studies carried out, such as age of the subjects and sample size in the study, different estimates of the prevalence of sleepiness are found. For instance, one review reported that about $20 \%$ of young adults had pathological sleepiness [6]. A Finnish study estimated the prevalence of having daytime sleepiness almost as $11 \%$ for women and $7 \%$ for men [7]. In a Swedish study, $12 \%$ of the

*Address correspondence to this author at the Department of Nursing, Umeå University, SE-901 87 Umeå, Sweden; Tel: +46907852114;

Fax: +46907852098; E-mail: Johannes.berg@pediatri.umu.se subjects reported insufficient sleep [8]. An American report from 1993 concluded that about 40 million Americans suffer from chronic sleep disorder. Another 20 to 30 million suffer from occasional sleep deprivation with a cost of 15.9 billion dollars for direct sleep disorders. As much as $\$ 150$ billion in sleepiness-related lost workplace productivity, accidents, and deaths have been reported [9]. More recent reports from the National Sleep Foundation indicate that a sizable proportion of adults $(37 \%)$ report that they are so sleepy during the day that it interferes with their daily activities a few days a month or more, and $16 \%$ experience this level of daytime sleepiness a few days per week or more [10]. It seems logical to reason that the prevalence of sleepy drivers on the road is higher than the prevalence of sleepiness related accidents. Results from prevalence studies vary. A Swedish study reported that $14 \%$ of long-haul drivers often or always are sleepy while driving [11]. A Finnish study found that about $40 \%$ of the long-haul truck drivers reported problems staying alert on average every fifth drive and over $20 \%$ had fallen asleep more than once while driving [12]. Another survey reported that $31 \%$ of the drivers admitted having dozed off at least once while driving during the previous twelve months. In a telephone survey in New York, it was found that about $55 \%$ of the drivers had been driving while sleepy and $23 \%$ had even fallen a sleep at the wheel [13]. Dawn [14] reported that $29 \%$ of the driving population had nodded off at least once in the previous year while driving. Twenty five percent of long-haul truck drivers reported that they had fallen asleep in the past year and about $47 \%$ had fallen asleep at the wheel in their trucks [15]. In a recent study, $22 \%$ of the lorry drivers reported that they had fallen asleep while driving. Thus, sleepiness both in general and with regard to driving is common, troublesome, costly and dangerous.

Sleepiness and its related aspects is a multidisciplinary field of research involving business, public interests, and governmental responsibilities. Attempts to solve or at least 
diminish the effects of sleepiness will require significant efforts. Society has great need for a better understanding of sleepiness including its causes, predictors, indicators, and the risks of being sleepy.

Thus, despite that the importance of sleepiness as a risk factor for accidents, in particular for transportation and health, has increased during the last decades, the knowledge about sleepiness still remains relatively unrecognized outside the sleep research field. The purpose of this overview was to describe some aspects of sleepiness, how they relate to each other by placing them in a simple model, a balance scale, and thereby facilitate the understanding of sleepiness to a wider audience. The model can be described as a balance scale (Fig. 1) that consists of six sleepiness related aspects: sleepiness (the arc), indicators of sleepiness (the arrow), sleep debt (the right bowl), countermeasures (the left bowl), circadian rhythm (the weight under the scale of balance), and risk of an accident (the wedge).

\section{SLEEPINESS}

Because clear definitions and terms of sleepiness are lacking, it is difficult to integrate the knowledge of sleep and wakefulness physiology into multidisciplinary thinking about driving while sleepy [16]. Sleepiness has been defined as the inability to stay awake - a drive to sleep [17] - however, other definitions have been used to describe a driver at risk of falling asleep. Hypersomnia, somnolence, sleep propensity, weariness, fatigue, tiredness, the ability to fall asleep, sleep ability, the ability to stay awake, sleepiness, and drowsiness are some examples [18]. However, it seems that the most commonly used terms in the literature are sleepiness, drowsiness, tiredness, and fatigue. In several studies, researchers use the term "sleepiness" [12, 19, 20]. Some researchers use the term "drowsiness" [21-23]. In a study of young male night drivers, the term "tiredness" was used, while "fatigue" was used in an overview of motor vehicle crashes [24, 25]. The different terms are often used synonymously. In a overview of sleepiness related accidents [26], "fatigue" and "sleepiness" are used synonymously to mean sleepiness resulting from the neurobiological regulating circadian rhythm and the drive to sleep. In a consensus statement about fatigue and accidents in transport operations, the term "fatigue" was used, but as pointed out, "fatigue" has been used synonymously with "drowsiness", "tiredness", and "sleepiness" [27]. In Merriam-Webster's Collegiate Dictionary, sleepy is defined as "ready to fall asleep," tired as

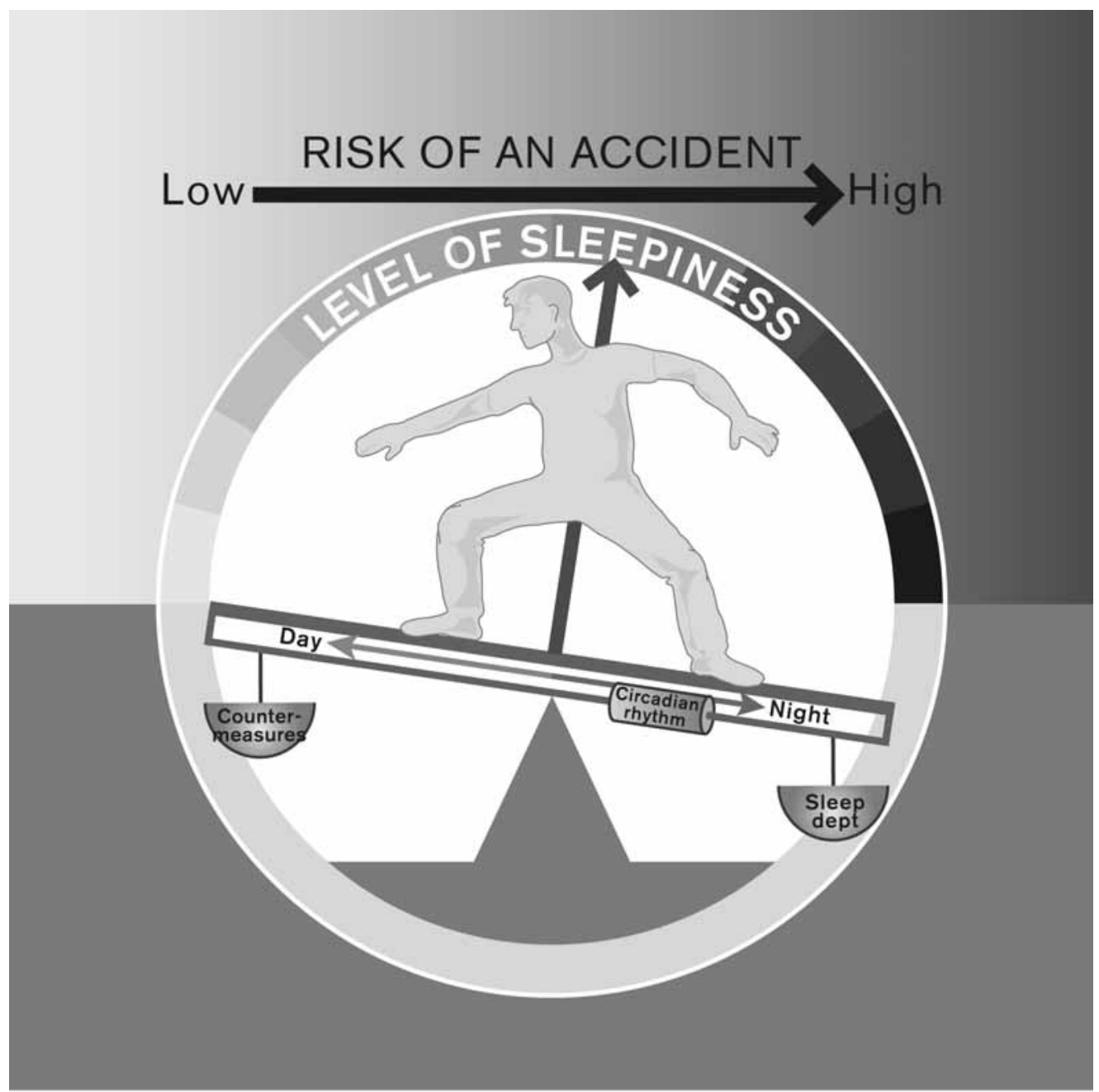

Fig. (1). The model, described as a balance scale model of consists of six sleepiness related aspects; level of sleepiness (the arc), indicators of sleepiness (the arrow on the scale of balance), sleep debt (the right bowl), countermeasures (the left bowl), circadian rhythm (the weight under the balance scale), and risk of an accident (the horizontal arrow). 
"drained of strength and energy", fatigue as "weariness or exhaustion from labour, exertion, or stress", and drowsy as "inducing or tending to induce sleep". Johns $[16,18]$ declares that the drowsy driver is in the state of drowsiness and this state, occurring at some point before sleep stage 1 , is a transitional state between wakefulness and sleep in which the sleep process already has begun and probably will lead to sleep. Furthermore, Johns distinguishes the state of drowsiness from sleepiness by saying that sleepiness is neither a state nor a process: it is the probability of falling asleep at a certain time $[16,18]$. Others have used a similar definition of sleepiness. Stutts et al. defined sleepiness as the inclination to sleep [28] and Åkerstedt and Kecklund [17] write that sleepiness is a part of the concept tiredness and describe it as an inability to stay awake - a drive to sleep. Johns [16] stresses further that his definition of sleepiness should be seen as a position along a continuum of arousal states from alert wakefulness to sleep and that it should be distinguished from the presence and intensity of feelings and symptoms that are related to the state of drowsiness, also called subjective sleepiness. Although fatigue is a recognized concept in driving research [29], conceptually it is easier to separate from drowsiness and sleepiness than drowsiness is from sleepiness. Fatigue can be defined as a psychological state in which individuals declare that they are unable to continue performing the task [29], or it can be defined as a subjective experience of tiredness and an inability to continue performing a task [25]. After a good night sleep followed by a strenuous training session, a person can experience fatigue without experiencing subjective sleepiness. As pointed out by Johns [16], one can doze off for a short period without experiencing fatigue. Definitions of concepts regarding drowsy driving are absent, but as Åkerstedt [30] has stated, such diversity is typical for a young research area. Nevertheless, it is important that this multidisciplinary research area develop a unified conceptual framework.

\section{THE SLEEP DEBT - THE RIGHT BOWL}

It is not completely known what actually causes sleepiness. The metaphor used here, it is not clear what changes the balance of the scale leading the indicator to point at higher levels of sleepiness. It has been argued that a boring, monotonous environment, heavy meal, or heat can cause sleepiness. On the other hand, one can state that the true reason for sleepiness is the same reasons that create a sleep debt (right bowl in Fig. 1). The greater the sleep debt is, the sleepier one will feel and the greater the propensity to fall asleep will be. The indicator points to a higher degree of sleepiness. With no sleep debt at all, one will not fall asleep. In this case, the indicator will point to zero sleepiness.

There are many causes that contribute to sleep debt, ranging from just going to bed too late the previous night to the disease fatal familial insomnia. One way to obtain an overview of the causes of sleepiness is by studying the classification of sleep disorders [31]. In an overview of this classification, these disorders are divided into four major groups: dyssomnias, parasomnias, medicopsychiatric, and proposed sleep disorders [32]. Dyssomnias, disorders that produce either insomnia or excessive sleepiness, are either intrinsic, for instance, narcolepsy and obstructive sleep apnea syndrome; extrinsic, for instance, inadequate sleep hygiene, high noise, and caffeine; or result from a disrupted circadian rhythm, for instance, shift work and jet leg. Parasomnias refer to disorders that are not abnormalities related to the sleep/wake states but rather to phenomena that often occur during sleep, such as sleep walking or sleep talking, which in turn can result in arousal or disturbing one's bed partner [32]. Medicopsychiatric sleep disorders are of medical or psychiatric origin that cause disturbed sleep. To describe all of these disorders is beyond this overview; however, a brief description of shift work sleep disorder is appropriate since professional driving often involves shift work.

\section{Shift Work and Sleepiness}

Today's 24-hour-7-day society requires organizations and arrangements where time constraints no longer limit human activities. Workers engaged in shift work, defined as work hours arranged in schedules with two or more shifts or permanent night, are estimated to be around $16 \%$ to $22 \%$ and a large proportion of these are in healthcare settings or in the transport industries [33-37]. Shift workers in general report more sleep disturbances than day workers, especially those working in three-shift schedules [38, 39]; however, there are individual differences. There are individuals whose sleep pattern or quality is not essentially impaired by rotating schedules or night schedules, whereas some people are more affected by schedules that interfere with the circadian sleepawake cycle [40, 41]. There are at least two major causes of sleepiness related to shift work: sleep loss and the conflict between the displaced work hours and the circadian rhythm [42]. For example, before the first night shift there is less sleep resulting in an extended period of wakefulness. Day sleep after night shift, is reported to be shorter and the loss affects REM-sleep more than stage- 4 sleep and the percentage of deep sleep is increased [42, 43]. As the circadian rhythm promotes sleep, work obligations force the shift worker to stay awake. A gradual phase shift of the circadian rhythm can occur over successive nights of shift work [41, 43].

\section{THE COUNTERMEASURES - THE RIGHT BOWL}

Sleep debt and external or internal stimulation (known in the literature as countermeasures) influence the level of sleepiness. With a small sleep debt, only a small amount of stimulation will balance the scale and thereby keep one awake. If sleep debt is greater, more stimulation is required to keep one awake [1].

The most obvious countermeasures in working life are conventional work hours and proper sleep hygiene [44, 45]. However, other obligations in life outside working hours might influence the effects of these countermeasures. Employing countermeasures during work hours or while driving may help prevent sleepiness related accidents. One way to categorise countermeasures is to divide them into sleep, drugs and food, environmental stimulation, and behaviours $[44,46]$.

\section{Sleep, Naps, or Breaks as a Countermeasure}

Napping is the most effective countermeasure against sleepiness. The most effective naps are 0.5 to $2 \mathrm{~h}$ that counteract the fall in alertness around the circadian low point during early morning [44]. An intervention study on the effect of napping among police who drive during night shift concluded that napping is an effective countermeasure for de- 
creased alertness and poor performance in driving tasks [47]. Napping in the afternoon among a group of long-haul drivers has positive effects on subjective sleepiness ratings, reaction times, and psychomotor performance measured during the night time [48]. Other studies have found that 15-minute naps during the night or early morning significantly counteract sleepiness $[49,50]$, whereas just taking a break was ineffective. Landström, et al. [51] found that truck drivers' EEG patterns showed a more altered state after a break in driving. In a flight simulator study, the effect of five short breaks spaced hourly during a 6-hour flight was compared with a control group who had one break in the middle of the flight. The experimental group showed significant reductions for 15 minutes post-break in physiological parameters as well as in alertness for up to 25 minutes post-break, indicating positive effects of short-duration breaks [52]. Nevertheless, while evidence of just taking a break may be elusive, there is strong evidence that sleep at work or naps before or during work is an effective countermeasure against sleepiness [44]. Because these naps decrease sleep debt, the weight in the left bowl is decreased (Fig. 1).

\section{Drugs and Food as Countermeasures}

There are studies that have investigated the effect of caffeine with or without a combination of a nap. Caffeine consumed in the early morning $(2-3$ cups of coffee) reduced lane drifting significantly for the first 30 minutes and reduced subjective sleepiness in a group of sleep deprived drivers [53]. A combination of caffeine and a nap is more effective in reducing lane drifting and subjective sleepiness than either one measure done in isolation $[49,50]$. Few studies have examined the effects of food and drink as countermeasures. One study indicated that intake of fructose or glucose had a similar stimulating effect on wakefulness immediately after intake, whereas the intake of fructose could lead to a delay in the development of drowsiness [54]. The effect of energy drinks given to sleepy subjects driving in a simulator showed an improvement in performance as measured by lane drifting and reaction time [55].

\section{Environmental Stimulation as Countermeasure}

Sudden noise has an arousing effect, making it a potential countermeasure [56, 57]. Waking sound that enhances wakefulness was studied in a laboratory setting and measured by EEG and subjective ratings. It was shown that the waking effect increased when sound varied in duration and frequency [57]. In a field study, a waking sound system was tested and it was found that exposure to the sounds was correlated to improvements of the immediate as well as the long-term self-reported changes in wakefulness [56]. Nevertheless, waking sound can be experienced as unpleasant. A more common sound in cars and trucks is the radio. Listening to the radio when driving, in laboratory settings, has been shown to reduce subjective sleepiness and was related to a trend of reduced lane drifting incidents [58]; however, it can also distract drivers from being aware of their sleepiness.

Because the circadian phase is closely linked to light, bright light seems to be a logical countermeasure to sleepiness. However, a field study with professional drivers trying a self-administered 30-minute light treatment in the middle of night driving showed no significant effect [59]. Another study tested whether 30 minutes of exposure to a bright light would reduce subjective sleepiness and EEG indicators of sleepiness, alpha and theta power density. Analysis showed that exposure to bright light significantly reduced subjective sleepiness but had no effects on alpha or theta power density. This suggests that a short exposure may not counteract sleepiness for a longer period following the exposure [60].

Laboratory studies investigating altering air temperature as a countermeasure to sleepiness are diverging. One study found that reductions of the air temperature by 10 degrees in repeated sequences significantly increased wakefulness [61]; another study showed no overall effects on incidents or lane drifting when using cold air as an "in-car" countermeasure to driver sleepiness [58].

However, it might be used temporarily to reduce sleepiness and provide the driver time to find a suitable place to stop.

\section{Behavioural Countermeasures}

The effect of exercise as a countermeasure for the sleepy driver is limited and has only a short term effect [62]. In a multinational study, drivers were asked what behaviours they used as countermeasures to prevent sleepiness while driving [46]. Most frequently used behaviours were turning up the volume of the radio, drinking caffeinated beverages, rolling down the window, and slapping and pinching one self. Less reported behaviours were trying not to stare at the division line, driving over rumble strips, chewing gum, smoking, conversing with someone, screaming, rotating drivers, or playing games in the car. Even if there is a lack of scientific evidence to support these behaviours, they may work for the individual, giving enough time to find a place to stop. However, most people, regardless of their occupation, level of education, and any other demographic characteristics, agreed that there is no substitute for sleep [46].

\section{INDICATORS OF SLEEPINESS - THE GAUGE}

An indicator of sleepiness plays an important role in measuring the level of sleepiness and thereby increases the ability to gauge when sleepiness becomes dangerous (Fig. 1). The level of sleepiness can be measured by objective and subjective indicators, but how these are related and how these indicate sleepiness over time is not completely understood. The indicator should preferably measure sleepiness correctly, precisely, easily, and rapidly. Some of the indicators are well studied while others are less studied, but they all have advantages and disadvantages. Furthermore, the implementation of the current knowledge of sleepiness and indicators into serial production of technical solutions in cars and trucks to prevent sleepiness while driving is still remarkable low.

\section{Objective Measures}

Electroencephalography (EEG) has been extensively investigated and shown to correlate with sleepiness [62-64]. Spectral analysis of a sleepy person's EEG often involves power density of alpha and theta activity. Alpha power density has been shown to increase in night workers compared to afternoon workers [65]. Other studies of night workers have shown an increase in alpha and theta activity as well as increases in self ratings of sleepiness during long night shifts $[63,66]$. Horne and Reyner $[49,50]$ have concluded that the 
combination of alpha and theta activity gives more consistent EEG results than if they are evaluated separately. Even if the interpretation of EEG signals is standardised, there is no standardised way to evaluate sleepiness using the EEG technique. Moreover, EEG measurements require a fair amount of expertise to record and to analyse. Currently, it seems impractical to use EEG as a routine method for analysing sleepiness in truck drivers.

The Multiple Sleep Latency Test (MSLT) is a laboratory method that evaluates daytime sleepiness. It is based on the assumption that the faster an individual falls asleep, the sleepier he must have been. The speed with which the individual falls asleep (sleep latency) can be used to evaluate the propensity for falling a sleep or sleepiness $[18,67,68]$. The MSLT is beneficial when diagnosing narcolepsy, and it is claimed that false-positive results are theoretically minimal [67]. On the other hand, it might be less sensitive if the person suffers from excessive daytime sleepiness with repeatedly low latencies, a floor effect [69]. False-negative results are possible because it takes a longer time for the subject to fall asleep than it usually does. Drawbacks of MSLT are that it does not take into account how the wires that are attached to the subject affect the ability to fall asleep and how the laboratory settings influences sleepiness compared to the subject's home environment [18]. MSLT has been studied in association with driving. A driving simulation study with sleep deprived subjects showed that MSLT correlated with performance as well as to the subjective sleepiness rating, but to a lesser degree [70].

Analysis of heart rate (HR) and heart rate variability (HRV) is a noninvasive technique that has been used to investigate the effects on cardiovascular autonomic regulation of work-related stresses [71]. HR has been shown to decrease during prolonged and monotonous driving, and sleepiness related to decrease in HR has been confirmed in laboratory studies [64, 72]. However, in a field study, no changes in HR related to sleepiness could be observed [73], whereas, in another study, an increase in HR in prolonged truck driving was found [74]. Egelund [73] analyzed HRV in subjects during a 4-hour drive and found a relationship between distance driven and low-frequency HRV. In another study, HRV was investigated in six long distance truck drivers. It was found that some HRV indices were higher during morning driving hours (8 a.m. to 12 p.m.) than during the afternoon hours (12 p.m. to 4 p.m.) [75]. Because the drivers also had different work assignments and napping periods, it is hard to interpret these results in terms of how sleepiness changes during long monotonous drives. A recent laboratory study concluded that HR and HRV were not reliable indicators of sleepiness [76].

Performance testing can be divided into psychomotor tasks (simple reaction time task) or cognitive tasks (memory tasks) [69]. Strong evidence suggests that sleepy people have impaired performance in both [4]. Tasks that demand continuous and frequent responding, such as simulated driving [19] or reaction time [77, 78], may have general slowing which could be evident nearly immediate with sleepiness. Vigilance tasks usually require the monitoring of a system with infrequent responses. Results from such tasks $[79,80]$ suggested that a task needed to be approximately 30 minutes or longer to show effects from one night's sleep deprivation. More recently, however, others studies have
More recently, however, others studies have demonstrated that a single night's sleep loss affected performance already from the first response on a 34-minute vigilance task requiring infrequent responding [81].

The role of head movement as an indicator of sleepiness has not been studied carefully enough. Head movement can be measured with an inclinometer [82] or with a video camera system [83]. Ji and Yang [83] noted that head position can reflect a person's level of sleepiness. Alert drivers normally look straight ahead; if a driver frequently looks in other directions for an extended time, the driver is either fatigued or inattentive. In an aviation study, head movements were measured among pilots [84]. During work, head movement is active, but when the pilots fell asleep, no head movements were recorded. In a laboratory study, head movement was measured among nonsleepy drivers. It was found that increased head movement appeared clearly after $150 \mathrm{~km}$ of a $300 \mathrm{~km}$ simulated monotonous driving [85]. In another laboratory study, sleep-deprived subjects had more head movements than when not sleep deprived [86].

Changes in eye parameters can indicate sleepiness. When a person is sleepy or falling asleep, the pupils constrict and become unstable due to changes in the autonomic nervous system. This phenomena has been used to measure sleepiness [67]. Although pupillography has been used to measure sleepiness, it would be impractical to use while driving [87]. Changes in eyelids have been studied using a real time detection system and have shown good correlation with vigilance tests $[88,89]$. Eye blink duration during on-road driving indicated that average blink duration was significantly reduced for bus drivers after treatment of their obstructive sleep apnea syndrome.

\section{Subjective Measures}

Well-known symptoms of sleepiness are eye problems, yawning, difficulties staying alert, and being less task focused. These and other symptoms have been studied [63, 90, 91]. General rating or specific ratings scales have been used extensively to measure subjective sleepiness. They are often easy to use and require little expertise to administer and interpret results. The literature on sleepiness often cites specific sleepiness scales such as Karolinska Sleepiness Scale (KSS), Stanford Sleepiness Scale (SSS), and the Epworth Sleepiness Scale, (ESS) [92-95]. Each scale measures different characteristics. Other more general scales are the Visual Analogue Scale (VAS) and the Category Ratio Scale (CR-10 scale) $[96,97]$.

The KSS is a bipolar scale with has nine categories (1 to 9) that cover the entire wakeful/sleepy continuum [93, 98]. Thus, some category and scale values on the upper end of scale are available for sleepiness ratings. The KSS was used in a study of long distance truck drivers and it was found that night drivers rated their sleepiness higher in proportion to increased alpha and theta activity [63]. The KSS has also been used to measure the effects of the countermeasures radio and cold air - on sleepiness among drivers who had their sleep restricted [58]. KSS scores were significantly lower when the radio was playing; however, the EEG showed no significant effects.

The Stanford Sleepiness Scale (SSS) is a bipolar scale that consists of seven descriptive statements such as "feeling 
active and vital, alert, wide awake" [95]. In a study with professional truck drivers under different types of driving regimes, the SSS was used to evaluate drivers level of sleepiness [99]. Results showed that drivers sleepiness during driving was more related to pretrip sleepiness rather than to any of the regimes.

The Epworth Sleepiness Scale (ESS) is a questionnaire that measures the subject's general level of daytime sleepiness. The ESS consists of eight different common situations in which the subjects rate their chances that they would doze off or fall asleep [94]. The ESS has been used in a survey of truck drivers that showed that a higher level of daytime sleepiness as rated by the ESS was related to more frequent drowsy driving [100]. In an other study of truck drivers, the ESS estimated sleep problems rather than finding a certain level of sleepiness that caused the drivers to stop driving and seek rest [12].

The Visual Analogue Scale (VAS) can measure several subjective phenomena commonly used in the assessment of pain. It is usually a $10-\mathrm{cm}$ line with end anchors labelled with the extremes of the phenomena to be measured [101]. Subjects can indicate their level of the phenomena being measured by making a mark on the line $[68,101]$. It can be used either as a unipolar scale, not sleepy to very sleepy, or as a bipolar scale, very alert to very sleepy [69]. In a study of young adult drivers, the unipolar scale version was used to investigate the relationship between perceived sleepiness while driving and a sleep model [102].

The Category Ratio Scale (CR-10), also called the Borgscale, combines level-anchored judgement aspects of a category scale with the growth rate determination possibilities of a ratio scale by using verbal labels on an open-ended number scale [96]. The CR-10 is a general scale that can be applied to various situations. Because it has a greater discrimination than the KSS and the SSS, it is easier to differentiate the rated symptoms, particularly at the lower end of the scale and at a higher level of intensity [103]. The CR-10 has been used to measure sleepiness in a laboratory setting and shown to correlate to both EEG and the KSS [104]. However, it has also been used when measuring perceived fatigue after mental work [105].

\section{THE CIRCADIAN RHYTHM - THE WEIGHT}

Sleepiness is also under the influence of the circadian rhythm in addition to sleep debt and the amount of external and internal stimulation. Simply speaking, one is usually sleepier at night than during the day. In Fig. (1), the circadian rhythm is illustrated by the weight hanging under the scale, which moves sideways depending on the time of day. A fundamental property in higher life forms is the ability to keep track of time [106]. One part of these time keeping systems is the circadian pacemaker, the biological clock [107]. The circadian pacemaker, which is located in suprachiamatic nucleus in the brain, generates the circadian rhythm with three characteristics; the rhythm is an endogenous and robust rhythm; its rhythm is roughly 24 hours (circadian, from the Latin circa and diem, meaning literally "around a day"), and the rhythm is in phase relative to the time of day [107]. This circadian pacemaker regulates the sleep and wake pattern as well as other behavioural, physiological, and biochemical rhythms, promoting being awake during the day time and sleep during night time [107, 108].

The circadian rhythm is primarily synchronized and entrained by the light-dark cycle with the function of adjusting life to a diurnal rhythm [107]. Other external clues that have been suggested to influence the circadian rhythm are exercise, social interaction, and sleep-wake schedules; however, these factors do not influence the circadian rhythm as significantly as light [107].

There is a relation with accidents due to sleepiness and the time of day. In a study that investigated drivers involved in sleep related vehicle accidents, three peaks during the twenty-four hour day were identified when accidents most often occurred: 2 a.m., 6 a.m., and 4 p.m. [109] Another database study including 4333 sleep related crashes showed that midnight to $7 \mathrm{a} . \mathrm{m}$. and the mid-afternoon (3.00 p.m.) were the most common periods for sleep related traffic accidents [110]. Similar results were found in a Finnish study that found an accident peak between midnight and 6:00 a.m. and another peak during the late afternoon [111]. In an American report of crashes due to driving while sleepy, $60 \%$ of the accidents occurred between 11 p.m. and 7 a.m. [13]. Sagberg [112] reported that $20 \%$ of the sleep related traffic accidents occurred during the night. A Swedish study of driving during the night showed an increase of the risk for accidents up to six times, peaking around 4 a.m., compared to before noon [113]. Authors of a review of sleep related vehicle accidents concluded that when driving around 6 a.m., drivers were 20 times more likely to fall asleep at the wheel than around 10 a.m. When driving around 4 p.m., the risk was three times higher [114]. NHTSA found similar results: late night and early morning or mid-afternoon are critical periods for sleepiness related accidents [22]. In a recent study, sleepiness among truck and bus drivers was reported by $46 \%$ of drivers to be most troublesome between 3 a.m. and 6 a.m., which confirms the above studies. However, when the drivers considered the time of year when sleepiness is most troublesome, $66 \%$ of the drivers reported autumn and $21 \%$ of the drivers reported winter [11]. Thus, besides the relations between sleepiness and the circadian rhythm, this supports a relation between sleepiness and season. This is, however, not thoroughly investigated with regard to sleepiness and traffic accidents.

There is strong evidence supporting a link between sleepiness related traffic accidents and time of day. The vulnerable hours from midnight to 7 a.m. and around 4 p.m. correspond very well to the circadian rhythm.

\section{RISK OF AN ACCIDENT - THE WEDGE}

An important questions is when does sleepiness become dangerous. If looking at accidents or incidents that occurred because of sleepiness, we could say that sleepiness was dangerous when the accident or incident occurred. However, a more proper question is: when is sleepiness undesired. Sleepiness can put people or your or property at risk. In general, sleepiness related accidents have been estimated to be $53 \%$ of all work related accidents and injuries [115]. Major accidents such as the nuclear disasters at Three Mile Island (1979) and Chernobyl (1986), the oil spill due to the Exxon Valdez crash (1989), and the poisonous gas leak from a pes- 
ticide factory in Bhopal, India (1984) were linked to sleepiness [26, 116].

Besides these headline disasters, sleepiness as a cause of incidents and accidents is frequently reported in the transport industry and to a lesser degree in health care settings [22, 117-121]. This is somewhat strange since the health care system, with a tradition of long work hours, altered schedules, and on-call periods, to a much greater extent allows longer work hours than for those in transportation [122].

It has been noted that "sleepiness is the largest identifiable and preventable cause of accidents in transport operations (between 15 and $20 \%$ of all accidents), surpassing that of alcohol or drug related incidents in all modes of transportation" [27]. Although it is obvious that sleep related accidents in transport operations should be recognized as a major traffic and work problem, it also applies to those driving to or from their work place, especially for risk groups such as shift-workers, people with untreated sleep apnea syndrome, and young people [22].

The lack of reliable methods to identify sleep related accidents and separate it from other types of accidents makes it difficult to determine the actual number of sleep related accidents and could lead to an underestimation of sleepiness as an explanation of an accident. These difficulties contribute to the fact that official statistics are often lower than estimates based on research $[17,46,114,123]$. Estimates of sleep related accidents vary. One English study found that $16 \%$ of all vehicle accidents on major roads were sleep related and $20 \%$ of the accidents on motorways were sleep related [109]. Another study estimated that $17 \%$ of road accidents are sleep related [124]. An American study estimated that 25\% - 35\% of accidents are related to sleepiness [125]. A Norwegian study, however, estimated only $3.9 \%$ of the road accidents were related to sleepiness [112]. A study involving heavy trucks estimated that $30 \%-40 \%$ of the accidents were related to sleepiness [126]. A study on two roads with heavy traffic found that $50 \%$ of fatal accidents were related to sleepiness [127].

Three main risk groups of drivers have been identified: male drivers aged 16 - 29 years, shift workers, and people with sleep problems [22]. Sleepiness is common among young male drivers when driving at night [24]. A study found that about $50 \%$ of the drivers involved in sleep related accidents were males under 30 years [109]. Similar results were obtained in an American study that found that drivers aged 25 years or younger were involved in $55 \%$ of sleepiness related crashes [128]. A Finnish study correlated age and time of day. They reported that the accident peak between midnight and 6:00 a.m. involved young drivers (18 to 20 years old), and the second peak during the late afternoon involved drivers 56 years or older [111].

Several studies have focused on driving conditions as contributing factors to sleep related accidents. Monotonous driving for longer periods, work related driving, and driving on a motorway are more likely to result in falling asleep at the wheel [114]. An American report found increased accidents rates on motorways and nonbuilt-up roads, $16-20 \%$, compared to built-up roads, 5\%, [129]. Roads in densely built-up areas are less associated with sleep related accidents due to the higher activity level, which can help the driver to stay alert [127]. In another study, drivers engaged in long distance driving reported significantly more often experiencing of sleepiness while driving than those driving in built-up areas. On the other hand, the same study identified prior sleep habits to be more contribute more to sleepiness while driving than working conditions [11]. Thus, monotonous driving conditions could be seen as less stimulation and thereby less weight in the left bowl (Fig. 1).

\section{CONCLUSIONS}

This overview describes important aspect of sleepiness and how they could be related. Sleep is a basic need and without enough sleep, we will become sleepy. Beside the unpleasant experience to fight sleepiness without being able to go to sleep, it can affect health both in the short and in the long run. Thus, a better understanding of sleepiness, the effects of sleepiness and how to prevent or cope with sleepiness is of importance. The balance scale, a metaphorical model, was made to facilitate the understanding of aspects of sleepiness. Key points in this overview were:

Clear definitions of sleepiness are lacking and several terms are used synonymously. A unified definition could enhance collaboration in a multidisciplinary research field.

There are several reasons that create a sleep debt. Shift workers are vulnerable to become sleepy during work hours, especially those working three-shift. Knowledge of sleepiness is therefore of importance for the staff managing working schedules.

Several countermeasures to sleepiness have been proven to be effective. However, the duration of the effect of these countermeasures varies and should not be consider as a substitute for sleep.

Indicators of sleepiness can be divided into objective and subjective measures. Objective measures, usually used in laboratory setting, have limitations in when it comes to practical implementation in daily life. Subjective measures, such as rating scales, are relatively easy to use. However, since the definition of sleepiness is lacking, sleepiness rating scales could be misinterpreted.

The risk of an accident, with no doubt, is linked to sleepiness. Major and minor accidents have been shown too caused by sleepiness. Preventing sleepiness by getting enough sleep seems to be most logical measure to deal with sleepiness. However, daily life and demands from the society and work often negatively influence the chance for regular sleep habits. Knowledge of the relation between sleepiness and aspects of sleepiness, especially accidents, might also increase the interest of measures that can prevent sleepiness.

\section{REFERENCES}

[1] Dement WC. What All Undergraduates Should Know About How Their Sleeping Lives Affect Their Waking Lives. Stanford University Center of Excellence for the Diagnosis and Treatment of Sleep Disorders. 1997 [cited 2005 Aug 24]. Available from: http://www.stanford.edu/ dement/sleepless.html.

[2] Harma M, Ilmarinen J. Towards the 24-hour society-new approaches for aging shift workers? Scand J Work Environ Health 1999; 25: 610-15.

[3] Rogers NL, Grunstein RR. 24/7 Health. Second annual Sleep Loss Symposium: working and sleeping around the clock. Med J Aust 2005; 182: 444-5. 
[4] Bonnet M. In: Kryger MH, Roth T, Dement WC, Eds. Principles and practice of sleep medicine. $3^{\text {rd }}$ ed. New York, W.B. Saunders Co. 2000; 53-71.

[5] Akerstedt T. Sömnens betydelse för hälsa och arbete [In Swedish]. Bauer Bok: Falun, 2002.

[6] Roehrs T, Carskadon MA, Dement WC, Roth T. In: Kryger MH, Roth T, Dement WC, Eds. Principles and practice of sleep medicine. $3^{\text {rd }}$ ed. New York, W.B. Saunders Co. 2000.

[7] Hublin C, Kaprio J, Partinen M, et al. Daytime sleepiness in an adult, Finnish population. J Intern Med 1996; 239: 417-23.

[8] Broman JE, Lundh LG, Hetta J. Insufficient sleep in the general population. Neurophysiol Clin 1996; 26: 30-9.

[9] Report of the National Commission on sleep disorders. Executive Summery and Executive Report. Wake up America: a national sleep alert. Washingthon DC: National Inst of Health, 1993.

[10] National Sleep Foundation. Sleep in America Poll. 2002 [cited 2005 Sep]; Available from: http://www.sleepfoundation.org

[11] van den Berg J, Landstrom U. Symptoms of sleepiness while driving and their relationship to prior sleep, work and individual characteristics. Transportation Research Part F: Traffic Psychol Behav 2006; 9: 207-26.

[12] Hakkanen H, Summala H. Sleepiness at work among commercial truck drivers. Sleep 2000; 23: 49-57.

[13] McCartt AT, Ribner SA, Pack AI, et al. The scope and nature of the drowsy driving problem in New York State. Accid Anal Prev 1996; 28: 511-7.

[14] Dawn R, Ed. National Survey of Distracted and Drowsy Driving Attitudes and Behavior: Findings. Washington, D.C., 2003; Vol. I.

[15] McCartt AT, Rohrbaugh JW, Hammer MC, et al. Factors associated with falling asleep at the wheel among long-distance truck drivers. Accid Anal Prev 2000; 32: 493-504.

[16] Johns MW. A sleep physiologist's view of the drowsy driver. Transportation Research Part F: Traffic Psychol Behav 2000; 3: 241-9.

[17] Akerstedt T, Kecklund G. Trötthet och trafiksäkerhet - en översikt av kunskapsläget [In Swedish]. Stockholm: Inst. för psykosocial medicine och Karolinska institutet, 2000.

[18] Johns MW. Rethinking the assessment of sleepiness. Sleep Med Rev 1998; 2: 3-15.

[19] Gillberg M, Kecklund G, Akerstedt T. Sleepiness and performance of professional drivers in a truck simulator-comparisons between day and night driving. J Sleep Res 1996; 5: 12-5.

[20] Connor J, Whitlock G, Norton R, et al. The role of driver sleepiness in car crashes: a systematic review of epidemiological studies. Accid Anal Prev 2001; 33: 31-41.

[21] Cummings P, Koepsell TD, Moffat JM, et al. Drowsiness, countermeasures to drowsiness, and the risk of a motor vehicle crash. Inj Prev 2001; 7: 194-9.

[22] NCSDR/NHTSA EXPERT PANEL. Drowsy Driving and Automobile Crashes. NHTSA People saving people. 2003 [cited 2004 nov 20]. Available from: http://www.nhtsa.dot.gov/people/injury/ drowsy_driving1/Drowsy.html

[23] Kircher A, Uddman M, Sandin J. Vechicle control and drowsiness. Linköping: Swedish national road and transport research institute, 2002.

[24] Corfitsen MT. Tiredness and visual reaction time among young male nighttime drivers: a roadside survey. Accid Anal Prev 1994; 26: 617-24.

[25] Brown ID. Driver fatigue. Hum Factors 1994; 36: 298-314.

[26] Dinges DF. An overview of sleepiness and accidents. J Sleep Res 1995; 4: 4-14.

[27] Akerstedt T. Consensus statement: fatigue and accidents in transport operations. J Sleep Res 2000; 9: 395.

[28] Stutts JC, Wilkins JW, Vaughn BV. Why Do People Have Drowsy Driving Crashes? Input from Drivers Who Just did: AAA Foundation for Traffic Safety. 1999 [cited 2004 dec12]. Available from: http://www.aaafoundation.org/pdf/sleep.pdf

[29] Hartley L. Fatigue \& Driving. Driver impairment, driver fatigue and driving simulation. Taylor \& Francis: London, 1995.

[30] Akerstedt T. Sleepiness. Sleep Med Rev 1998; 2: 1-2.

[31] American Sleep Disorders Association. International Classification of Sleep Disorders: Diagnostic and Coding Manual. American Sleep Disorders Association: Rochester, 1997.

[32] Thorpy MJ. In: Kryger MH, Roth T, Dement WC, Eds. Principles and practice of sleep medicine. New York, W.B. Saunders Co. 2000 .
[33] Boisard P, Cartron D, Gollac M, et al. Time and work: duration of work. Dublin, Ireland: European Foundation for the Improvement of Living and Working Conditions; 2003 [cited 2005 Sept 16]. Available from: www.eurofound.eu.int

[34] Basner RC. Shift-work sleep disorder--the glass is more than half empty. N Engl J Med 2005; 353: 519-21.

[35] Boggild H, Suadicani P, Hein H, et al. Shift work, social class, and ischaemic heart disease in middle aged and elderly men; a 22 year follow up in the Copenhagen Male Study. Occup Environ Med 1999; 56: 640-5.

[36] Drake C, Roehrs T, Richardson G, et al. Shift work sleep disorder: prevalence and consequences beyond that of symptomatic day workers. Sleep 2004; 27: 1453-62.

[37] Akerstedt T, Torsvall L, Gillberg M. Sleepiness in shiftwork. A review with emphasis on continuous monitoring of EEG and EOG. Chronobiol Int 1987; 4: 129-40.

[38] Harma M, Tenkanen L, Sjoblom T, et al. Combined effects of shift work and life-style on the prevalence of insomnia, sleep deprivation and daytime sleepiness. Scand J Work Environ Health 1998; 24: 300-7.

[39] Akerstedt T. Shift work and disturbed sleep/wakefulness. Sleep Med Rev 1998; 2: 117-28.

[40] Leproult R, Colecchia EF, Berardi AM, et al. Individual differences in subjective and objective alertness during sleep deprivation are stable and unrelated. Am J Physiol Regul Integr Comp Physiol 2003; 284: R280-R90.

[41] Costa G. Shift work and occupational medicine: an overview. Occup Med 2003; 53: 83-8.

[42] Akerstedt T. Sleepiness as a consequence of shift work. Sleep 1988; 11: 17-34.

[43] Akerstedt T. Shift work and disturbed sleep/wakefulness. Occup Med (Lond) 2003; 53: 89-94.

[44] Akerstedt T, Landstrom U. Work place countermeasures of night shift fatigue. Int J Ind Ergon 1998: 21: 167-78.

[45] MacLean AW, Davies DR, Thiele K. The hazards and prevention of driving while sleepy. Sleep Med Rev 2003; 7: 507-21.

[46] Nguyen LT, Jauregui B, Dinges DF. Changing behaviors to prevent drowsy driving and promote traffic safety: review of proven, promising and unproven techniques. AAA Foundation for Traffic Safety: Pennsylvania 1998.

[47] Garbarino S, Mascialino B, Penco MA, et al. Professional shiftwork drivers who adopt prophylactic naps can reduce the risk of car accidents during night work. Sleep 2004; 27: 1295-302.

[48] Macchi MM, Boulos Z, Ranney T, et al. Effects of an afternoon nap on nighttime alertness and performance in long-haul drivers. Accid Anal Prev 2002; 34: 825-34.

[49] Horne JA, Reyner LA. Counteracting driver sleepiness: effects of napping, caffeine, and placebo. Psychophysiology 1996; 33: 306-9.

[50] Reyner LA, Horne JA. Suppression of sleepiness in drivers: combination of caffeine with a short nap. Psychophysiology 1997; 34: 721-5.

[51] Landstrom U, Lindblom-Haggqvist S. Low frequency noise in lorries and correlation effects on drivers. J Low Freq Noise Vib 1988; 7: 104-9.

[52] Neri DF, Oyung RL, Colletti LM, et al. Controlled breaks as a fatigue countermeasure on the flight deck. Aviat Space Environ Med 2002; 73: 654-64.

[53] Reyner LA, Horne JA. Early morning driver sleepiness: effectiveness of $200 \mathrm{mg}$ caffeine. Psychophysiology 2000; 37: 251-6.

[54] Landstrom U, Knutsson A, Lennernas M, et al. Laboratory studies of the effects of carbohydrate consumption on wakefulness. Nutr Health 2000; 13: 213-25.

[55] Horne JA, Reyner LA. Beneficial effects of an "energy drink" given to sleepy drivers. Amino Acids 2001; 20: 83-9.

[56] Landstrom U, Englund K, Nordstrom B, et al. Sound exposure as a measure against driver drowsiness. Ergonomics 1999; 42: 927-37.

[57] Landstrom U, Englund K, Nordstrom B, et al. Laboratory studies of a sound system that maintains wakefulness. Percept Mot Skills 1998; 86: 147-61.

[58] Reyner LA, Horne JA. Evaluation "in-car" countermeasures to sleepiness: cold air and radio. Sleep 1998; 21: 46-50.

[59] Landstrom U, Akerstedt T, Bystrom M, et al. Effect on truck drivers' alertness of a 30-min. exposure to bright light: a field study. Percept Mot Skills 2004; 98: 770-6. 
[60] Akerstedt T, Landstrom U, Bystrom M, et al. Bright light as a sleepiness prophylactic: a laboratory study of subjective ratings and EEG. Percept Mot Skills 2003; 97: 811-9.

[61] Landstrom U, Englund K, Nordstrom B, et al. Laboratory studies on the effects of temperature variations on drowsiness. Percept Mot Skills 1999; 89: 1217-29.

[62] Horne JA, Reyner LA. Driver sleepiness. J Sleep Res 1995; 4: 239.

[63] Kecklund G, Akerstedt T. Sleepiness in long distance truck driving: an ambulatory EEG study of night driving. Ergonomics 1993; 36: $1007-17$.

[64] Lal SK, Craig A. A critical review of the psychophysiology of driver fatigue. Biol Psychol 2001; 55: 173-94.

[65] Akerstedt T, Kecklund G, Knutsson A. Manifest sleepiness and the spectral content of the EEG during shift work. Sleep 1991; 12: 221 5.

[66] Torsvall L, Akerstedt T. Sleepiness on the job: continuously measured EEG changes in train drivers. Electroencephalogr Clin Neurophysiol 1987; 66: 502-511.

[67] Mitler M, Carskadon M, Hirshkowitz M. In: Kryger MH, Roth T, Dement WC, Eds. Principles and Practice of Sleep Medicine. $3^{\text {rd }}$ ed. New York, W.B. Saunders 2000; 1251-7.

[68] Kushida C. Sleep deprivation. Clinical issues, pharmacology and sleep loss effect. Lung Biology in health and disease. New York, Marcell Dekker 2005.

[69] Curcio G, Casagrande M, Bertini M. Sleepiness: evaluating and quantifying methods. Int J Psychophysiol 2001; 41: 251-63.

[70] Pizza F, Contardi S, Mostacci B, et al. A driving simulation task: correlations with Multiple Sleep Latency Test. Brain Res Bull 2004; 63: 423-6.

[71] Task Force of the european society of cardiology the north american society of pacing. Heart rate variability: Standards of Measurement, Physiological Interpretation, and Clinical Use. Circulation 1996; 93: 1043-65.

[72] O'Hanlon JF, Ed. Heart rate variability: A new index of driver alterness/fatigue. Automotive Engineering Congress; 1972; Detroit, USA. Society of Automotive Engineers, INC. Pennsylvania, New York 1972.

[73] Egelund N. Spectral analysis of heart rate variability as an indicator of driver fatigue. Ergonomics 1982; 25: 663-72.

[74] Apparies R, Riniolo T, Porges S. A psychophysiological investigation of the effects of driving longer-combination vehicles. Ergonomics 1998; 41: 581-92.

[75] Sato S, Taoda K, Kawamura M, et al. Heart rate variability during long truck driving work. J Hum Ergol (Tokyo) 2001; 30: 235-40.

[76] van den Berg J, Neely G, Wiklund U, et al. Heart rate variability during sedentary work and sleep in normal and sleep-deprived states. Clin Physiol Funct Imaging 2005; 25: 51-7.

[77] Lisper HO, Kjellberg A. Effects of 24-hour sleep deprivation on rate of decrement in a 10-minute auditory reaction time task. J Exp Psychol 1972; 96: 287-90.

[78] Dinges DF, Powell JW. Sleepiness impairs optimum response capability. Sleep Res 1989; 18: 366.

[79] Wilkinson RT. Interaction of lack of sleep with knowledge of results, repeated testing, and individual differences. J Exp Psychol 1961; 62: 263-71.

[80] Wilkinson RT. The effect of lack of sleep on visual watch-keeping. Q J Exp Psychol 1960; 12: 36-40.

[81] Gillberg M, Akerstedt T. Sleep loss and performance: no "safe" duration of a monotonous task. Physiol Behav 1998; 64: 599-604.

[82] Akesson I, Hansson GA, Balogh I, et al. Quantifying work load in neck, shoulders and wrists in female dentists. Int Arch Occup Environ Health 1997; 69: 461-74.

[83] Ji Q, Yang X. Real-time eye, gaze, and face pose tracking for monitoring driver vigilance. Real-Time Imaging 2002; 8: 357-377.

[84] Wright N, McGown A. Vigilance on the civil flight deck: incidence of sleepiness and sleep during long-haul flights and associated changes in physiological parameters. Ergonomics 2001; 44: 82106.

[85] Popieul J, Simon P, Loslever P. Using Driver's Head Movements Evolution as a Drowsiness Indicator: 2003: Proceedings of the IEEE Intelligent Vehicles Symposium. Columbus, Ohio, USA 2003.

[86] van den Berg J. Sleepiness and Head movements. Ind Health 2006; 44: 564-76.
[87] Wilhelm H, Wilhelm B. Clinical applications of pupillography. J Neuroophthalmol 2003; 23: 42-9.

[88] Wierwille WW, Ellsworth LA, Wreggit SS, et al. Research on vehicle-based driver status/performance monitoring: Development, validation, and refinement of algorithms for detection of driver drowsiness. National Highway Traffic Safety Administration: Washington DC 1994.

[89] Dinges DF, Grace R. PERCLOS: A valid psychophysiological measure of alertness as assessed by psychomotor vigilance. U.S Department of transportation. Federal highway Administration. Washington D.C. 1998.

[90] Milosevic S. Drivers' fatigue studies. Ergonomics 1997; 40: 381-9.

[91] Nilsson T, Nelson TM, Carlson D. Development of fatigue symptoms during simulated driving. Accid Anal Prev 1997; 29: 479-88.

[92] Horne JA, Reyner LA, Barrett PR. Driving impairment due to sleepiness is exacerbated by low alcohol intake. Occup Environ Med 2003; 60: 689-92.

[93] Akerstedt T, Gillberg M. Subjective and objective sleepiness in the active individual. Int J Neurosci 1990; 52: 29-37.

[94] Johns MW. A new method for measuring daytime sleepiness: the Epworth sleepiness scale. Sleep 1991; 14: 540-5.

[95] Hoddes E, Zarcone V, Smythe H, et al. Quantification of sleepiness: a new approach. Psychophysiology 1973; 10: 431-6.

[96] Borg G. In: Geissler H, Petzold P, Eds. Psychophysical Judgment and the Process of Persception. Berlin, VEB Deutscher Verlag der Wissenschaften 1982; 25-34.

[97] Capodaglio EM. Comparison between the CR10 Borg's scale and the VAS (visual analogue scale) during an arm-cranking exercise. J Occup Rehabil 2001; 11: 69-74.

[98] Gillberg M, Kecklund G, Akerstedt T. Relations between performance and subjective ratings of sleepiness during a night awake. Sleep 1994; 17: 236-41.

[99] Williamson AM, Feyer AM, Friswell R. The impact of work practices on fatigue in long distance truck drivers. Accid Anal Prev 1996; 28: 709-19.

[100] Baas PH, Charlton SG, Bastin GT. Survey of New Zealand truck driver fatigue and fitness for duty. Transportation Research Part F: Traffic Psychol Behav 2000; 3: 185-93.

[101] Wewers ME, Lowe NK. A critical review of visual analogue scales in the measurement of clinical phenomena. Res Nurs Health 1990; 13: 227-36.

[102] Smith S, Carrington M, Trinder J. Subjective and predicted sleepiness while driving in young adults. Accid Anal Prev 2005: 106673.

[103] Neely GW. Category-ratio scaling of sensory magnitude in comparison with ther methods. Stockholm: University 1995.

[104] van den Berg J, Neely G, Nilsson L, et al. Electroencephalography and subjective ratings of sleep deprivation. Sleep Med 2005; 6: 231-40.

[105] Ahsberg E, Gamberale F, Gustafsson K. Perceived fatigue after mental work: an experimental evaluation of a fatigue inventory. Ergonomics 2000; 43: 252-68.

[106] Hastings M. The brain, circadian rhythms, and clock genes BMJ 1998; 317: 1704-7.

[107] Czeisler CA, Khalsa SBS. In: Kryger MH, Roth T, Dement WC, Eds. Principles and practice of sleep medicine. $3^{\text {rd }}$ ed. New York, W.B. Saunders Co 2000.

[108] Turek F. In: Kryger MH, Roth T, Dement WC, Eds. Principles and practice of sleep medicine. 3 Ed. New York, W.B. Saunders Co 2000.

[109] Horne JA, Reyner LA. Sleep related vehicle accidents. BMJ 1995; 310: 565-7.

[110] Pack AI, Pack AM, Rodgman E, et al. Characteristics of crashes attributed to the driver having fallen asleep. Accid Anal Prev 1995; 27: 769-75.

[111] Summala H, Mikkola T. Fatal accidents among car and truck drivers: effects of fatigue, age, and alcohol consumption. Hum Factors 1994; 36: 315-26.

[112] Sagberg F. Road accidents caused by drivers falling asleep. Accid Anal Prev 1999; 31: 639-49.

[113] Akerstedt T, Kecklund G, Horte LG. Night driving, season, and the risk of highway accidents. Sleep 2001; 24: 401-6.

[114] Horne JA, Reyner LA. Vehicle accidents related to sleep: a review. Occup Environ Med 1999; 56: 289-94. 
[115] Leger D. The cost of sleep-related accidents: a report for the National Commission on Sleep Disorders Research. Sleep 1994; 17: 84-93.

[116] Folkard S, Lombardi DA, Tucker PT. Shiftwork: safety, sleepiness and sleep. Ind Health 2005; 43: 20-3.

[117] Powell NB, Schechtman KB, Riley RW, et al. Sleepy driving: accidents and injury. Otolaryngol Head Neck Surg 2002; 126: 21727.

[118] Garbarino S, Nobili L, Beelke M, et al. The contributing role of sleepiness in highway vehicle accidents. Sleep 2001; 24: 203-6.

[119] Hakkanen H, Summala H. Fatal traffic accidents among trailer truck drivers and accident causes as viewed by other truck drivers. Accid Anal Prev 2001; 33: 187-96.

[120] Landrigan CP, Rothschild JM, Cronin JW, et al. Effect of reducing interns' work hours on serious medical errors in intensive care units. N Engl J Med 2004; 351: 1838-48.

[121] Lockley SW, Cronin JW, Evans EE, et al. Effect of reducing interns' weekly work hours on sleep and attentional failures. N Engl J Med 2004; 351: 1829-37.

[122] Howard SK, Gaba DM, Rosekind MR, et al. The risks and implications of excessive daytime sleepiness in resident physicians. Acad Med 2002; 77: 1019-25.
[123] RoSPA. Driver fatigue and road accidents: A literature review and position paper. Birmingham, UK: The Royal Society For The Prevention Of Accidents. 2001 [cited 2005 Nov 1]. Available from: http://www.rospa.com/roadsafety/info/fatigue.pdf

[124] Johnson K. Put Drowsy Driving to Rest. National Safety Council, USA 1998.

[125] Fell D. Safety Update: Problem Definition and Countermeasure Summary: Fatigue. New South Wales: New South Wales Road Safety Bureau 1994

[126] National Transportation Safety Board. Safety Study. Factors That Affect Fatigue In Heavy Truck Accidents. Washington 1996.

[127] Reissman C. The Alert Driver: A Trucker's Guide to Sleep, Fatigue, and Rest in our 24-Hour Society. American Trucking Associations: Alexandria 1996

[128] Garder P. Shoulder Rumble Strips For Improving Safety On Rural Interstates - Year One. Department of Civil and Environmental Engineering: Maine 1994.

[129] Maycock G. Driver Sleepiness as a Factor in Car and HGV Accidents. Transport Research Laboratory: Crawthorne 1995.

(C) Johannes van den Berg; Licensee Bentham Open.

This is an open access article licensed under the terms of the Creative Commons Attribution Non-Commercial License (http://creativecommons.org/licenses/by-nc/3.0/) which permits unrestricted, non-commercial use, distribution and reproduction in any medium, provided the work is properly cited. 